\title{
Differential gene expression in response to cold stress in Lepidium apetalum during seedling emergence
}

\author{
H.X. ZHAO ${ }^{1,2}$, Q. $\mathrm{LI}^{1}$, G. $\mathrm{LI}^{1}$ *and Y. DU ${ }^{2}$ \\ College of Life Science and Technology, Xinjiang University, Urumqi 830046, P.R. China ${ }^{1}$ \\ College of Life Science, Xinjiang Normal University, Urumqi 830053, P.R. China ${ }^{2}$
}

\begin{abstract}
Germination of Lepidium apetalum Wild. seeds is invariably arrested by cold stress. cDNA-amplified fragment length polymorphism (AFLP) technique was used to isolate genes relevant to chilling stress $\left(4^{\circ} \mathrm{C}\right)$ during seedling emergence. 43 transcript-derived fragments (TDFs) were found to be up-regulated and 17 down-regulated during chilling stress. Eighteen TDF of up-regulated genes were cloned and sequenced. Some of these genes are involved in the stress response, some play important roles in energy and substrate metabolism, and some encode unknown proteins such as TDF119. Two sequences, designated TDF217 and TDF223, may correspond to novel genes. The expression profiles of 6 from 18 TDFs were analyzed by quantitative real-time PCR under chilling and abscisic acid (ABA) stress. It was demonstrated that all 6 genes were significantly induced by chilling and their expression was decreased when the temperature was shifted from 4 to $25^{\circ} \mathrm{C}$. The transcriptional levels of 5 TDFs were strongly enhanced also in response to exogenous ABA. Based on the characteristics of genes isolated from seedlings exposed to cold stress, we conclude that Lepidium adapts to cold stress by regulating many signal transduction pathways, including both ABA-dependent and ABA-independent signaling pathways.
\end{abstract}

Additional key words: AFLP, chilling, quantitative real-time PCR.

\section{Introduction}

Lepidium (Lepidium apetalum Wild.), a member of Cruciferae, is distributed throughout Asia and Europe (Zhou and Guo 1987). It is a traditional Chinese herb with the effects on relieving asthma, inducing diuresis and diminishing swelling (Xiao 2002). Lepidium is a of spring ephemeral plants that could germinate under low temperatures. Therefore it is regarded as a good material to study the cold tolerance mechanisms during plant germination (Zhao et al. 2010).

To survive stresses, efficient resistance is required for the plants (Hu et al. 2010). The tolerance of plants to low temperature during seedling emergence is mainly determined by genetic factors that were selected during plant evolution in existing environments (Ismail and Hall 2002). Acclimation to cold stress involves a number of biochemical and physiological changes, including increased contents of soluble sugars, proteins, amino

acids and organic acids, as well as modifications in membrane lipid composition (Guy 1990, Walker et al. 2010). Many of these changes are regulated by the altered expression of genes encoding lipid transfer proteins, lateembryogenesis-abundant proteins, alcohol dehydrogenase, translation elongation factor, and other proteins with unknown functions (Thomashow 1999, Seki et al. 2001, 2002, Fowler and Thomashow 2002). For example, the overproduction of glycine betaine (GB) could enhance cold-stress tolerance of wheat by protecting plasma membranes (Zhang et al. 2010). Although it is recognized that the mechanisms by which plants cope with low-temperature stress are complex and multigenic (Hughes and Dunn 1996, Thomashow 1998), the complex molecular changes that occur after cold stress remain unclear.

Gene expression profiles can be obtained and

Received 22 April 2010, accepted 6 January 2011.

Abbreviations: AFLP - amplified fragment length polymorphism; qRT-PCR - quantitative real-time polymerase chain reaction; TDFs - transcript-derived fragments

Acknowledgements: We are grateful to Prof. X. Zhao for collection and identification of seeds and to Prof. J. Qin for great help with the experiments. This work was supported by the Key Scientific Projects for Supporting Xinjiang Uygur Autonomous Region in China (No. 200840102-40).

*Corresponding author; fax: (+86) 991 8581106, e-mail: guanli@xju.edu.cn 
compared using various methods (Donson et al. 2002). cDNA-amplified fragment length polymorphism (AFLP) is an efficient, sensitive, and reproducible technique for the isolation of differentially expressed genes (Bachem et al. 1996, Vuylsteke et al. 2006). In this study, this method was used to characterize and analyze gene expression during Lepidium seedling emergence under $4{ }^{\circ} \mathrm{C}$ and to identify genes and pathways that may play a

\section{Materials and methods}

Lepidium apetalum Wild. seeds were collected from Liyu Mountain in Urumqi, Xinjiang Uygur Autonomous Region and kept at $4{ }^{\circ} \mathrm{C}$ after drying at room temperature. Sterilized seeds were sown in half-strength Murashige and Skoog (MS) medium and stored in the cold $\left(4{ }^{\circ} \mathrm{C}\right)$ for $2 \mathrm{~d}$ for stratification. Then the seeds were allowed to germinate at $25{ }^{\circ} \mathrm{C}$ in a plant growth room for $60 \mathrm{~h}$, at which time cotyledons emerged from the seed capsule.

For cold treatment, seedlings were exposed to temperature of $4{ }^{\circ} \mathrm{C}$ for 3 and $6 \mathrm{~h}$, respectively. The control plants were kept at $25{ }^{\circ} \mathrm{C}$. All treatments were done under the same irradiance of $14.5 \mathrm{~W} \mathrm{~m}^{-2}$.

An additional experiment involving quantitative realtime polymerase chain reaction (qRT-PCR) was conducted. After the cold exposure for different time periods $(1,3,6,12$, and $24 \mathrm{~h})$, total RNA was isolated from half of the seedlings in each sample. The other half of the seedlings in each sample was treated at $25{ }^{\circ} \mathrm{C}$ for $6 \mathrm{~h}$ before total RNA isolation. Some additional plants were treated with ABA $(100 \mu \mathrm{M})$ (Cheng et al. 2009a,b) for 0,1 or $6 \mathrm{~h}$, and then were used for total RNA isolation.

Total RNA was isolated from about $100 \mathrm{mg}$ of fresh seedlings using the Trizol $^{\mathrm{TM}}$ extraction method (Invitrogen, Carlsbad, CA, USA). Double-stranded cDNA was synthesized using the $M-M L V$ RTase cDNA synthesis kit (TaKaRa, Kyoto, Japan) from $3 \mu \mathrm{g}$ total RNA according to the manufacturer's instructions.

About $500 \mathrm{ng}$ of double-stranded cDNA was subjected to standard AFLP template production using the method of Vos et al. (1995). The restriction enzymes used for digestion of cDNA were EcoRI and MseI (New England Biolabs, Beverly, MA, USA). The digested products were ligated to adapters with sequences as follows: EcoRI adapter, 5'-CTCGTAGACTGCGTACC-3', 3'-CTGACGCATGGTTAA-5'; MseI adapter, 5'-GAC

\section{Results and discussion}

Identification of cold-induced transcripts: All 64 selected primer combinations were used for AFLP analysis of the cDNA from Lepidium seedlings at three different stages. A representative silver-stained cDNA- role in chilling tolerance. The resulting survey of overall differential gene expression patterns in Lepidium to cold stress provides deeper insight into gene function and a more comprehensive knowledge of the complex processes that occur during the environmental responses of these and other ephemeral plants during seedling emergence.

GATGAGTCCTGAG-3', 3'-TACTCAGGACTCAT-5'. The ligated products were pre-amplified using the corresponding pre-amplification primers (EcoRI: 5'-GACTGCGTACCAATTC-3', MseI: 5'-GATGAG TCCTGAGTAA-3'). Preamplified products were amplified with 64 combination primers corresponding to selective nucleotides at the 3 ' end (EcoRI: AA, AC, AT, AG, CA, CC, CTCG; MseI: CC, CG, CA, CT, TA, TC, TG, TT). The AFLP products were analyzed on $8 \%$ polyacrylamide gels in TBE electrophoresis buffer. The gels were silver stained using silver nitrate according to Guo et al. (2006).

Polymorphic transcript-derived fragments (TDFs), identified based on their presence, absence or differential intensity, were cut from the gel and eluted. Eluted DNA $\left(0.005 \mathrm{~cm}^{3}\right)$ was amplified in the pre-amplification PCR cycle described above, using the same primers that were used for the pre-amplification reaction of cDNA-AFLP analysis. The PCR products which ranged from 100 to $300 \mathrm{bp}$ were isolated, eluted and ligated into the $p M D 18-T$ simple vector $(\mathrm{TaKaR} a)$. After the isolated cold-induced TDFs were cloned, each was sequenced and its distinct nucleotide sequence was subjected to a homology search of the NCBI database using BLAST.

qRT-PCR using Power SYBR green dye (Applied Biosystems, Shanghai, China) was performed to select TDFs representing unknown genes that may play a role in cold responses. The elongation factor 1-alpha, a constitutive protein, was used as an internal control. PCR was performed in triplicate for each sample. The amount of transcript of each gene of interest normalized to that of the internal control gene was analyzed using the 2-Delta DeltaC(T) method (Livak and Schmittgen 2001). The primers used for qRT-PCR were designed based on the selected sequences of the TDFs using Primer Express v. 3.0 (Table 1).

AFLP gel with clear and unambiguous bands (TDFs) is shown in Fig. 1. A total of 217 TDFs were isolated based on their presence/absence (qualitative variants) or on differences in their levels of expression (quantitative 
Table 1. Primers used for real-time PCR amplification and the resulting amplicon size.

\begin{tabular}{lllr}
\hline TDFS & Forward primers 5'-3' & Reverse primers 5'-3' & Products length [bp] \\
\hline ef1 & CAAGGCTAGGTACGAT & CAATCATGTTGTCTCCCT & 119 \\
107 & CGGAACAGTAGATGACA & TAGTTCATGCCTGATGTC & 125 \\
119 & GTTCAATGTCATCTTCTTC & GTGAATACCATAGCAGTC & 109 \\
217 & TAACCACCAAATCACACC & ACTGTGAAAATGCTCATA & 98 \\
223 & TGAGATGCATGATTGC & TAGTAGAAACAGAACT & 127 \\
205 & CCAAAGAACTCTAGAGA & TGAAAGGTGTCTCAGCTGT & 105 \\
120 & CACGACTATATATAGCAC & CCGTTGTGAGTAGACAAA & 164 \\
\hline
\end{tabular}

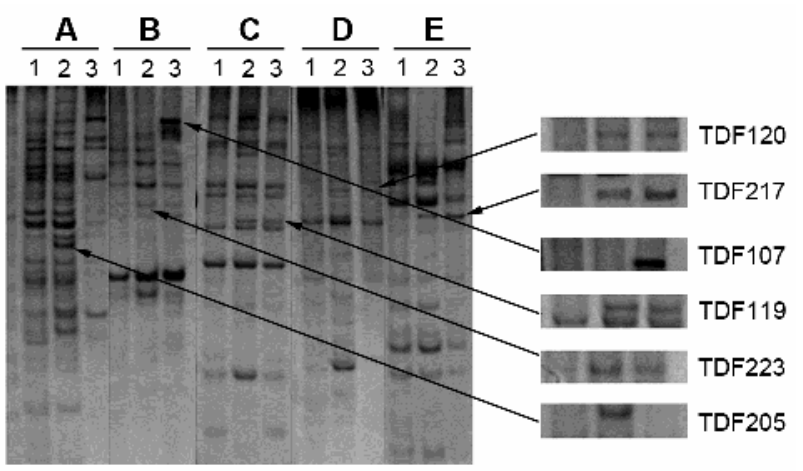

Fig. 1. Partial detail of a silver-stained cDNA-AFLP gel showing the differential expression of genes detected with 5 of 64 primer combinations. Six TDFs isolated from cDNA-AFLP were selected for qRT-PCR analysis. 1 - seedling chilled at $4{ }^{\circ} \mathrm{C}$ for $0 \mathrm{~h} ; 2$ - seedling chilled at $4{ }^{\circ} \mathrm{C}$ for $3 \mathrm{~h} ; 3$ - seedling chilled at $4{ }^{\circ} \mathrm{C}$ for $6 \mathrm{~h}$. A, B, C, D, E - cDNA-AFLP with different primer combinations. Arrows designate TDFs that differ significantly in expression after chilling and that were selected for analysis expression profiling.

variants). Of 217 TDFs, we found 60 based on qualitative expression differences and 157 that showed quantitative differences in expression. Of these 60 TDFs, 43 were present in cold treated plants and 17 were present in control plants.

Sequencing and sequence analysis: In our study, 18 expected differentially expressed TDFs were successfully eluted from polyacrylamide gels, reamplified and sequenced. The results of databank searching (Table 2) revealed that these TDFs are related to other genes involved in stress responses. The biological role of some of the cloned genes can be inferred from their sequence similarities to genes that code for previously studied proteins of both plant and non-plant origin. We found that some of the cloned genes are involved in stress responses and some play important roles in energy and substrate metabolism. However, the majority of the cold-induced or repressed genes encode proteins whose roles cannot be predicted from their primary amino acid sequences; the biological activity of these proteins remains to be determined. Two of the sequences, TDF217 and TDF223, resulted in few hits, suggesting that they may correspond to novel genes.

TDF102 encodes a putative protein that shows high sequence similarity to the photosystem 2 (PS 2) polypeptide. It has been reported that exposure to low temperature results in the decomposition of PS 2 D1 protein, decrease in electron tranport activity and so depression of PS 2 activity (Allen and Ort 2001, Liu et al. 2002, Van Heerden et al. 2003, Strauss et al. 2006). TDF102 enhanced translation may help Lepidium seedlings adjust photosynthesis under cold stress.

TDF105 showed $91 \%$ sequence similarity with eukaryotic translation initiation factor 3E (EIF3E). The eIF3 is the largest of 12 known translation initiation factors. It associates with the $40 \mathrm{~S}$ ribosome and stimulates the binding of Met-tRNA ${ }_{i}^{\text {Met }}$ in partial reactions reconstituted in vitro with purified mammalian eIFs (Trachsel and Staehelin 1979). Recent reports show that eIF3 is a five-lobed particle, an $750-\mathrm{kDa}$ complex that controls the assembly of $40 \mathrm{~S}$ ribosomal subunits on messenger RNAs (mRNAs) bearing either a 5'-cap or an internal ribosome entry site (IRES) and promotes initiation complex assembly (Siridechadilok et al. 2005, Baird et al. 2007, Zhou et al. 2008). TDF105 was upregulated significantly when Lepidium seedlings were exposed to $4{ }^{\circ} \mathrm{C}$; this implies that eIF3 plays an important potential role during low-temperature stress. However, the details of its role in translation initiation under cold conditions are still unknown.

Glutaredoxin was first identified by Holmgren (1976). Recent progress in our understanding of the glutaredoxin system has linked redox potential in cells to the regulation of multitude processes, including sulfhydryl homeostasis, signaling transduction, cell apoptosis and cell proliferation. In plant cells under chilling, the elimination of the excess generation of reactive oxygen species (ROS) is important in plant resistance mechanisms. One of the TDFs identified in this study, TDF114, which was up-regulated when the seedlings were stressed at $4{ }^{\circ} \mathrm{C}$ for 3 or $6 \mathrm{~h}$, showed homology to a gene encoding a putative glutaredoxin family protein. This implies that increased TDF114 expression may improve the ability of Lepidium to tolerate lowtemperature stress by reducing the toxicity of ROS brought about by cold stress. 
Table 2. Nucleotide homologies of the transcript-derived fragments (TDFs) to known gene sequences in the database using the $B L A S T N$ algorithm along with the expression pattern.

\begin{tabular}{lllll}
\hline TDFs & Homology to gene (GeneBank accession number) & Organism & E-value & Identities \\
\hline 102 & putative photosystem 2 polypeptide (AY084512.1) & Arabidopsis thaliana & $7 \mathrm{e}-048$ & $172 / 196(87 \%)$ \\
105 & EIF3E (eukaryotic translation initiation factor 3E (NM_115589.4) & Arabidopsis thaliana & $5 \mathrm{e}-024$ & $84 / 92(91 \%)$ \\
107 & adenylate kinase family protein (AL161563.2) & Arabidopsis thaliana & $5 \mathrm{e}-011$ & $47 / 50(94 \%)$ \\
112 & thioesterase family protein (NM_103729.3) & Arabidopsis thaliana & $7 \mathrm{e}-034$ & $100 / 108(92 \%)$ \\
114 & glutaredoxin family protein (NM_115566.3) & Arabidopsis thaliana & $4 \mathrm{e}-017$ & $83 / 92(90 \%)$ \\
117 & universal stress protein (NM_180232.2) & Arabidopsis thaliana & $3 \mathrm{e}-010$ & $67 / 77(87 \%)$ \\
119 & unknown protein (NM_118635.4) & Arabidopsis thaliana & $5 \mathrm{e}-032$ & $103 / 113(91 \%)$ \\
120 & peroxisomal targeting signal type 1 receptor protein (NM_125012.4) & Arabidopsis thaliana & $9 \mathrm{e}-010$ & $52 / 56(92 \%)$ \\
123 & SCARECROW transcriptional regulator-like (NM_124630.4) & Arabidopsis thaliana & $3 \mathrm{e}-038$ & $189 / 224(84 \%)$ \\
125 & glycine dehydrogenase (decarboxylating) (NM_119455.2) & Arabidopsis thaliana & $3 \mathrm{e}-059$ & $161 / 175(92 \%)$ \\
127 & armadillo/beta-catenin repeat family protein (NM_111006.2) & Arabidopsis thaliana & $6 \mathrm{e}-026$ & $95 / 103(92 \%)$ \\
205 & ETT (ETTIN); transcription factor (ETT) (NM_128946.3) & Arabidopsis thaliana & $3 \mathrm{e}-030$ & $91 / 98(92 \%)$ \\
206 & ribulose bisphosphate carboxylase (RBCS1A) (NM_202369.2) & Arabidopsis thaliana & $3 \mathrm{e}-050$ & $125 / 132(94 \%)$ \\
207 & chitinase, putative (NM_129921.5) & Arabidopsis thaliana & $2 \mathrm{e}-044$ & $136 / 150(90 \%)$ \\
217 & a novel zinc finger protein (CU464125.6) & zebrafish & 0.002 & $28 / 29(96 \%)$ \\
223 & mitogen-activated protein kinase 1 (EU332852.1) & Homo sapiens & 0.041 & $23 / 23(100 \%)$ \\
228 & wound-induced basic protein (NM_111603.2) & Arabidopsis thaliana & $3 \mathrm{e}-037$ & $109 / 118(92 \%)$ \\
232 & basic leucine zipper transcription factor (AY322555.1) & Cucumis sativus & 9e-019 & $114 / 135(84 \%)$ \\
\hline
\end{tabular}

A putative partial protein encoded by TDF107 has a sequence similar to those of adenylate kinase family proteins. The adenylate kinase (AK, EC 2.7.4.3) prevents marked increases in the ATP/ADP ratio at the site of energy generation and marked decreases in the ratio at the site of ATPase, doubling the efficiency of the diffusion of ATP in the transfer of energy and maintaining efficient intracellular energy flow (Dzeja and Terzic 2003). Recently, a series of studies showed that AK regulates the membrane $\mathrm{K}^{+}$-ATP channel (Stanojevic et al. 2008) and ATP-binding cassette (ABC) transporter activity (Randak and Welsh 2005) and is required for extracellular ATP synthesis (Choo et al. 2008).

The sequence of TDF205 is highly similar to that of transcription factors (ETT). Evidence shows that overexpression of transcription factors can markedly enhance the stress tolerance of plants (Kasuga et al. 1999, Winicov and Bastola 1999, Kong et al. 2004, Yu and Tang 2004). Increased levels of transcription factors CBF1 and $\mathrm{CBF} 2$ and 3 induced CBF-targeted gene expression and increased low-temperature resistance in plants (Jaglo-Ottosen et al. 1998, Maruyama et al. 2004, Vogel et al. 2005). TDF205 was responsive to low temperature in this experiment. Further study is required to determine whether TDF205 enhances Lepidium seedling endurance at low temperature.

The TDF232 sequence is similar to that of the gene for basic leucine zipper transcription factor. Basic leucine zipper (bZIP) transcription factors are present exclusively in eukaryotes; they constitute one of the largest and most diverse transcription factor families. In plants, bZIP transcription factors have been reported to regulate a variety of biological processes including pathogen defense (Thurow et al. 2005), photomorphogenesis and light signaling (Mallappa et al. 2006), and seed maturation and germination (Chern et al. 1996). The bZIP transcription factors are characterized by the presence of a conserved bZIP domain (Hurst 1995).

The sequence of TDF119 is fairly similar to an Arabidopsis thaliana sequence that codes for an unknown protein. The question of whether elevated TDF119 expression is specific to chilling-resistant Lepidium during seedling emergence should be further explored.

The sequences of TDF217 and TDF223 are not highly similar to any sequences in the NCBI database. However, TDF2 17 possesses a small degree of homology to a gene for a novel zinc finger protein. It is reported that zinc finger protein can increase plant survival in adaptation to stresses, particularly biotic stresses and play important roles in gene expression, cellular differentiation, embryogenesis, and disease (Bellefroid et al. 1998, Holmes et al. 1999). TDF223 has some homology with the gene for mitogen-activated protein kinase 1 (MAPK1). Several studies have shown that protein kinases with high sequence similarity to mammalian MAPKs are found in plants, and it has become apparent that MAPK cascades play very important roles in signal transduction pathways of plants, including those involved in abiotic and biotic stress signaling (Ichimura et al. 2000, Nuhse et al. 2000, Petersen et al. 2000).

Gene expression analysis: Cold acclimation involves the remodeling of cell and tissue structures and the reprogramming of metabolism and gene expression (Thomashow 1999, Viswanathan and Zhu 2002). QRT-PCR was performed on six of the TDFs (TDF107, 
$119,217,223,205$ and 120) to validate the changes in mRNA abundance in chilling seedlings and ABA-treated seedlings. It was found that the expression pattern of these cDNA fragments was similar in cDNA-AFLP and qRT-PCR analysis. The results demonstrated that these six TDFs showed various levels of differential expression after $0-24 \mathrm{~h}$ of cold stress and $6 \mathrm{~h}$ of ABA exposure.

It is universally believed that plants have two ways to adapt to abiotic stresses: ABA-dependent and ABAindependent signaling pathways (Yamaguchi-Shinozaki and Shinozaki 2005). Both the two ways involve different transcription factors from stress signal perception to gene expression (Agarwal and Jha 2010). With the exception of TDF217, the six TDFs identified in this study showed strongly enhanced transcriptional levels in response not only to chilling but also to exogenous application of ABA. Therefore, these five genes appear to be involved in ABA-dependent signaling pathways in response to chilling stress. Many cold-regulated genes in plants are induced by $\mathrm{ABA}$ as well as by cold. ABA-responsive genes invariably possess an ACGT motif, which is essential for ABA regulation ( $\mathrm{Nag}$ et al. 2005). Additionally, low-temperature activation of the C-repeat element activation (CRT) may also occur through a novel ABA signaling pathway (Thieringer et al. 1998). Sequence analysis of the six cold-responsive genes identified in this study showed that TDF119 possesses an ACGT motif; whether the other five TDFS possess ACGT or CRT motifs is still unknown based on the partial sequences that we have identified.

TDF217 was responsive only to low temperature; treatment with $\mathrm{ABA}$ did not change its transcriptional level. This suggests that TDF217 is part of an ABAindependent signaling pathway that functions in cold stress.

The expression levels of the six identified coldresponsive genes declined when the seedlings were transferred to $25{ }^{\circ} \mathrm{C}$ for $6 \mathrm{~h}$ after $4{ }^{\circ} \mathrm{C}$ chilling; however, their expression levels did not decrease to that of the control.

Expression of TDF119 on exposure to low temperature at different growth stages: The protein encoded by TDF119 is unknown (Table 2). We determined that the expression of TDF119 increased between 1 and $24 \mathrm{~h}$ after $4{ }^{\circ} \mathrm{C}$ chilling and was upregulated by $\mathrm{ABA}$, implying that the protein encoded by TDF119 plays a role in an ABA-dependent signaling pathway that is affected by cold stress at seedling emergence. We further tested whether the increased expression of TDF119 in Lepidium in response to chilling occurs only during seedling emergence. The study showed that TDF119 was induced at high levels by exposure to low temperature during seedling emergence (radicle protrusion, radicle protraction, hypocotyl protrusion); TDF119 expression showed lower sensitivity to cold stress during plant growth than during seedling emergence, although its expression increased to a small extent at the stages of third leaf emergence and flowering. This result shows that TDF119 plays an important role in responses to low temperature during germination of Lepidium.

\section{References}

Agarwal, P.K., Jha, B.: Transcription factors in plants and ABA dependent and independent abiotic stress signaling. - Biol. Plant. 54: 201-212, 2010.

Allen, D.J., Ort, D.R.: Impacts of chilling temperatures on photosynthesis in warm-climate plants. - Trends Plant Sci. 6: 36-42, 2001.

Bachem, C.W., Van der Hoeven, R.S., De Bruijn, S.M., Vreugdenhil, D., Zabeau, M., Visser, R.G.: Visualization of differential gene expression using a novel method of RNA fingerprinting based on AFLP: analysis of gene expression during potato tuber development. - Plant J. 9: 745-753, 1996.

Baird, S.D., Lewis, S.M., Turcotte, M., Holcik, M.: A search for structurally similar cellular internal ribosome entry sites. Nucl. Acids Res. 35: 4664-4677, 2007.

Bellefroid, E.J., Sahin, M., Poncelet, D.A., Riviere, M., Bourguignon, C., Martial, J.A., Morris, P.L., Pieler, T., Szpirer, C., Ward, D.C.: Kzf1 - a novel KRAB zinc finger protein encoding gene expressed during rat spermatogenesis. - Biochim biophys Acta. 1398: 321-329, 1998.

Cheng, L.B., Huan, S.T., Sheng, Y.D., Hua, X.J., Shu, Q.Y., Song, S.Q., Jing, X.M.: GMCHI, cloned from soybean [Glycine max (L.) Meer.], enhances survival in transgenic Arabidopsis under abiotic stress. - Plant Cell Rep. 28: 145-
153, 2009a.

Cheng, L.B., Li, S.Y., He, G.Y.: Isolation and expression profile analysis of genes relevant to chilling stress curing seed imbibition in soybean [Glycine max (L.)Meer.]. - Agr. Sci. China 8: 521-528, 2009b.

Chern, M.S., Eiben, H.G., Bustos M.M.: The developmentally regulated bZIP factor ROM1 modulates transcription from lectin and storage protein genes in bean embryos. - Plant J. 10: $135-148,1996$.

Choo, H.J., Kim, B.W., Kwon, O.B., Lee, C.S., Choi, J.S., Ko, Y.G.: Secretion of adenylate kinase 1 is required for extracellular ATP synthesis in $\mathrm{C} 2 \mathrm{C} 12$ myotubes. - Exp. mol. Med. 40: 220-228, 2008.

Donson, J., Fang, Y., Espiritu-Santo, G., Xing, W., Salazar, A., Miyamoto, S., Armendarez, V., Volkmuth, W.: Comprehensive gene expression analysis by transcript profiling. - Plant mol. Biol. 48: 75-97, 2002.

Dzeja, P.P., Terzic, A.: Phosphotransfer networks and cellular energetics. - J. exp. Biol. 206: 2039-2047, 2003.

Fowler, S., Thomashow, M.F.: Arabidopsis transcriptome profiling indicates that multiple regulatory pathways are activated during cold acclimation in addition to the CBF cold response pathway. - Plant Cell 14: 1675-1690, 2002.

Guo, J.R., Schnieder, F., Verreet, J.A.: Differences between the 
fingerprints generated from total RNA and poly-A RNA using a modified procedure of cDNA-AFLP and silver staining. - Biotechnol Lett. 28: 267-270, 2006.

Guy, C.: Cold acclimation and freezing stress tolerance: role of protein metabolism. - Annu. Rev. Plant. Physiol Plant mol. Biol. 41: 187-223, 1990.

Holmes, D.I., Wahab, N.A., Mason, R.M.: Cloning and characterization of ZNF236, a glucose-regulated Kruppellike zinc-finger gene mapping to human chromosome 18q22-q23. - Genomics 60: 105-109, 1999.

Holmgren, A.: Hydrogen donor system for Escherichia coli ribonucleoside-diphosphate reductase dependent upon glutathione. - Proc. nat. Acad. Sci. USA 73: 2275-2279, 1976.

Hughes, M.A., Dunn, M.A.: The molecular biology of plant acclimation to low temperature. - J. exp. Biol. 47: 291-305, 1996.

Hurst, H.C.: Protein Profile. - Academic Press, London 1995.

Hu, X.J., Zhang, Z.B., Xu, P., Fu, Z.Y., Hu, S.B. Song, W.Y.: Multifunctional genes: the ross-talk among the regulation networks of abiotic stress responses. - Biol. Plant. 54: 213223, 2010.

Ichimura, K., Mizoguchi, T., Yoshida, R.: Various abiotic stresses rapidly activate Arabidopsis MAP kinases ATM PK and ATM PK 6. - Plant J. 24: 655- 665, 2000.

Ismail, A.M., Hall, A.E.: Variation in traits associated with chilling tolerance during emergence in cowpea germplasm. - Field Crops Res. 77: 99-113, 2002.

Jaglo-Ottosen, K.R., Gilmour, S.J., Zarka, D.G., Schabenberger, O., Thomashow, M.F.: Arabidopsis CBF1 overexpression induces COR genes and enhances freezing tolerance. Science 280: 104-106, 1998.

Kasuga, M., Liu, Q., Miura, S., Yamaguchi-Shinozaki, K., Shinozaki, K.: Improving plant drought, salt, and freezing tolerance by gene transfer of a single stress-inducible transcription factor. - Nat. Biotechnol. 17: 287-291, 1999.

Kong, J., Cao, W.H., Zhang, J.S.: Transgenic analysis of a salt inhibited OsZFP1 gene fromrice. - Acta bot. sin. 46: 573577, 2004.

Liu, P., Zhao, S., Meng, Q.W., Wei, Y.Y., Zou, Q.: Effects of cold hardening on photosynthetic performance and chilling induced photo inhibition in sweet pepper leaves. - Plant Physiol. mol. Biol. 28: 51-58, 2002.

Livak, K.J., Schmittgen, T.D.: Analysis of relative gene expression data using real-time quantitative PCR and the 2(-Delta Delta C(T)) method. - Methods 25: 402-408, 2001.

Mallappa, C., Yadav, V., Negi, P., Chattopadhyay, S.: A basic leucine zipper transcription factor, G-box-binding factor 1, regulates blue light-mediated photomorphogenic growth in Arabidopsis. - J. biol. Chem. 281: 22190-22199, 2006.

Maruyama, K., Sakuma, Y., Kasuga, M., Ito, Y., Seki, M., Goda, H., Shimada, Y., Yoshida, S., Shinozaki, K., Yamaguchi-Shinozaki, K.: Identification of cold-inducible downstream genes of the Arabidopsis DREB1A/CBF3 transcriptional factor using two microarray systems. - Plant J. 38: 982-993, 2004.

Nag, R., Maity, M.K., Dasgupta, M.: Dual DNA binding property of ABA insensitive 3 like factors targeted to promoters responsive to ABA and auxin. - Plant mol. Biol. 59: 821-838, 2005.

Nuhse, T.S., Peck, S.C., Hirt, H., Boller, T.: Microbial elicitors induce activation and dual phosphorylation of the Arabidopsis thaliana MAPK 6. - J. biol. Chem. 275: 7521-
7526,2000

Petersen, M., Brodersen, P., Naested, H., Andreasson, E., Lindhart, U., Johansen, B., Nielsen, H.B., Lacy, M., Austin, M.J., Parker, J.E., Sharma, S.B., Klessig, D.F., Martienssen, R., Mattsson, O., Jensen, A.B., Mundy, J.: Arabidopsis MAP kinase 4 negatively regulates systemic acquired resistance. - Cell 103: 1111-1120, 2000.

Randak, C.O., Welsh, M.J.: Adenylate kinase activity in ABC transporters. - J. biol. Chem. 280: 34385-34388, 2005.

Seki, M., Narusaka, M., Abe, H., Kasuga, M., YamaguchiShinozaki, K., Carninci, P., Hayashizaki, Y., Shinozaki, K.: Monitoring the expression pattern of 1300 Arabidopsis genes under drought and cold stresses by using a full-length cDNA microarray. - Plant Cell 13: 61-72, 2001.

Seki, M., Narusaka, M., Ishida, J., Nanjo, T., Fujita, M., Oono, Y., Kamiya, A., Nakajima, M., Enju, A., Sakurai, T., Satou, M., Akiyama, K., Taji, T., Yamaguchi-Shinozaki, K., Carninci, P., Kawai, J., Hayashizaki, Y., Shinozaki, K.: Monitoring the expression profiles of 7000 Arabidopsis genes under drought, cold and high-salinity stresses using a full-length cDNA microarray. - Plant J. 31: 279-292, 2002.

Siridechadilok, B., Fraser, C.S., Hall, R.J., Doudna, J.A., Nogales, E.: Structural roles for human translation factor eIF3 in initiation of protein synthesis. - Science 310: 15131515, 2005.

Stanojevic, V., Habener, J.F., Holz, G.G., Leech, C.A.: Cytosolic adenylate kinases regulate K-ATP channel activity in human beta-cells. - Biochem. biophys. Res. Commun. 368: 614-619, 2008.

Strauss, A.J., Kruger, G.H.J., Strasser, R.J., Van Heerden, P.D.R.: Ranking of dark chilling tolerance in soybean genotypes probed by the chlorophyll $a$ fluorescence transient O-J-I-P. - Environ. exp. Bot. 56: 147-157, 2006.

Thieringer, H.A., Jones, P.G., Inouye, M.: Cold shock and adaptation. - Bioessays 20: 49-57, 1998.

Thomashow, M.F.: Role of cold-responsive genes in plant freezing tolerance. - Plant Physiol. 118: 1-8, 1998.

Thomashow, M.F.: Plant cold acclimation: freezing tolerance genes and regulatory mechanisms. - Annu. Rev. Plant Physiol. Plant mol. Biol. 50: 571-599, 1999.

Thurow, C., Schiermeyer, A., Krawczyk, S., Butterbrodt, T., Nickolov, K., Gatz, C.: Tobacco bZIP transcription factor TGA2.2 and related factor TGA2.1 have distinct roles in plant defense responses and plant development. - Plant J. 44: 100-113, 2005.

Trachsel, H., Staehelin, T.: Initiation of mammalian protein synthesis. The multiple functions of the initiation factor eIF3. - Biochim. biophys. Acta 565: 305-314, 1979.

Van Heerden, P.D., Tsimilli, M.M., Kruger, G.H., Strasser, R.J.: Dark chilling effects on soybean genotypes during vegetative development: parallel studies of $\mathrm{CO}_{2}$ assimilation, chlorophyll a fluorescence kinetics O-J-I-P and nitrogen fixation. - Physiol Plant. 117: 476-491, 2003.

Viswanathan, C., Zhu, J.K.: Molecular genetic analysis of coldregulated gene transcription. - Phil. Trans. roy. Soc. London B Biol. Sci. 357: 877-886, 2002.

Vogel, J.T., Zarka, D.G., Van Buskirk, H.A., Fowler, S.G., Thomashow, M.F.: Roles of the CBF2 and ZAT12 transcription factors in configuring the low temperature transcriptome of Arabidopsis. - Plant J. 41: 195-211, 2005.

Vos, P., Hogers, R., Bleeker, M., Reijans, M., Van de Lee, T., Hornes, M., Frijters, A., Pot, J., Peleman, J., Kuiper, M... AFLP: a new technique for DNA fingerprinting. - Nucl. 


\section{H.X. ZHAO et al.}

Acids Res. 23: 4407-4414, 1995.

Vuylsteke, M., Daele, H., Vercauteren, A., Zabeau, M., Kuiper, M.: Genetic dissection of transcriptional regulation by cDNA-AFLP. - Plant J. 45: 439-446, 2006.

Walker, D.J., Romero, P., Correal, E.: Cold tolerance, water relations and accumulation of osmolytes in Bituminaria bituminosa. - Biol. Plant. 54:293-298, 2010.

Winicov, I.I., Bastola, D.R.: Transgenic overexpression of the transcription factor alfin1 enhances expression of the endogenous MsPRP2 gene in alfalfa and improves salinity tolerance of the plants. - Plant Physiol. 120: 473-480, 1999.

Yamaguchi-Shinozaki, K., Shinozaki, K.: Organization of cisacting regulatory elements in osmotic- and cold-stressresponsive promoters. - Trends Plant Sci. 10: 88-94, 2005.

Xiao, P.G.: Modern Chinese Materia Medica. Vol. 2. Chemical Industry Press, Beijing 2002.

$\mathrm{Yu}$, S.W., Tang, K.X.: MAP kinase cascades responding to environmental stress in plants. - Acta bot. sin. 46: 127-136,
2004.

Zhang, X.Y., Liang, C., Wang, G. P., Luo, Y., Wang, W.: The protection of wheat plasma membrane under cold stress by glycine betaine overproduction. - Biol. Plant. 54: 83-88, 2010.

Zhao, H.X., Li, Q., Zhou, J., Li, G.: The characteristics of low temperature tolerance during seed germination of the ephemeral plant lepidium. - Acta bot. yunnanica 32: 448454, 2010.

Zhou, M., Sandercock, A.M., Fraser, C.S., Ridlova, G., Stephens, E., Schenauer, M.R., Yokoi-Fong, T., Barsky, D., Leary, J.A., Hershe, J.W.: Mass spectrometry special feature: mass spectrometry reveals modularity and a complete subunit interaction map of the eukaryotic translation factor eIF3. - PNAS 105: 18139-18144, 2008.

Zhou, T.Y., Guo, R.L.: Flora of China. - Beijing Science and Technology Press, Beijing 1987. 